\title{
The Role of Context in Defining Play
}

Ciera Crowell

University Pompeu Fabra

08018 Barcelona, Spain

ciera.crowell@upf.edu

Joan Mora-Guiard

University Pompeu Fabra

08018 Barcelona, Spain

joan.mora@upf.edu
Narcis Pares

University Pompeu Fabra

08018 Barcelona, Spain

narcis.pares@upf.edu

Permission to make digital or hard copies of part or all of this work for personal or

classroom use is granted without fee provided that copies are not made or distributed for profit or commercial advantage and that copies bear this notice and the full citation on the first page. Copyrights for third-party components of this work must be honored. For all other uses, contact the owner/author(s).

CHI PLAY'18 Extended Abstracts, Oct. 2831, 2018, Melbourne, Australia.

Copyright is held by the author/owner(s).

ACM ISBN 978-1-4503-5968-9/18/10.

https://doi.org/10.1145/3270316.3271538

\begin{abstract}
When players enter into an interactive game setting, they undertake a process of discovery and subsequent distinguishing of the rules and goals which will prevail in the play context. However, this process of forming understanding is often altered by the subtle expectations which prevail upon the interaction setting. In this paper, we argue that user perception is shaped differently depending on the general context on how and where players first encounter the game. We will use an existing three phase gameplay model, based on invitation, exploration, and immersion, and draw observations from laboratory, museum, hospital, and classroom studies of various interactive playful experiences. This work aims to support interaction designers towards positive gameplay experiences for children and lessening the gap between laboratory and in situ studies.
\end{abstract}

\section{CCS Concepts}

•Human-centered computing $\rightarrow \mathrm{HCl}$ theory, concepts and models;

\section{Author Keywords}

Human Computer Interaction; Full-Body Interaction; Play;

Autism Spectrum Conditions 


\section{Introduction}

In designing full-body interactive experiences, designers aim to help the user understand that the target play objects or spaces bring intrinsic rules based on their affordances [6], while the user also goes defining those rules subjectively as they engage with the experience. In this process, the user creates their own circle of understanding which will dictate their experience as they play. As the interface, on its physical and software levels, connects players with the game [8], most designers focus on designing the play artifact to shape user understanding of the experience [2] However, the role that context can have in influencing a user's understanding of the system must also be considered by designers of playful experiences, as users do not tend to engage with an interactive system in an isolated manner, but rather in a meaningful social context and in a context of practice [1]

This paper takes a closer look into the understanding formed by users as they become acquainted with an interactive system, and how designers can take into account contextual elements when designing these experiences. Specifically, we will analyze our experiences when creating experimental procedures in laboratory, hospital, exhibition, and classroom settings, aiming to highlight important differences when introducing these experiences to children. These differences might cause problems when designing interactive games for controlled trials and their subsequent transfer to natural settings. We will rely upon a 3 phase model of play: invitation, exploration, immersion [3], and how a system's context can affect these phases. Our study aims to aid in teraction designers to not only consider the design of the interactive system (i.e. interfaces and content) but also the external factors of deployment.

\section{Interaction as a multiple stage model}

The idea of interactivity as a multiple stage model, beginning with a system's invitation to engage with the user, was described by Polaine [7] as a concept including four principal parts: invitation to play, the playing field and rules, challenge, and open-endedness. This model was later abridged by de Valk, et al [3], to compose the three phase model of open ended play: invitation, exploration, and immersion.

One important aspect from both models is the placement of curiosity as the driver of interest in the initial stage of play, as users may begin by watching others play or observing a hint of interactivity in the play setting. When users begin to experiment with possibilities of the system, they begin the exploration stage, where they determine the various interaction opportunities offered by the play setting.

\section{Design Cases}

In this study we address four full-body interactive playful experiences which were tested in either experimental, school, hospital and exhibition contexts. The discussion follows with an analysis of patterns which were consistently observed in various settings.

\section{Experience 1: GenPlay}

GenPlay is a full-body interactive system designed for classroom use, consisting of a floor projection of approximately $2.5 \times 3$ meters in area. The system is meant to be a collaborative activity which fosters socialization between children as they explore the interaction possibilities of the openended design featuring generative audiovisual effects.

GenPlay was tested at a mainstream elementary school in Netherlands with 57 children between the ages of 9-11. The system was installed for two days in a spare classroom in the school that children visited for music classes. On the first day of the study, children played in the virtual environ- 


\begin{tabular}{lll}
\hline GenPlay & Foster collaboration between classmates through open-ended play & Classroom \\
\hline Lands of Fog & Scaffold social initiation between children with ASD and partners & Laboratory, Classroom, Museum \\
\hline Pico's Adventure & Elicit social behaviors in children with ASD collaboratively & Hospital, Museum \\
\hline NanoZoom & Explore the nanoscale world & Laboratory, Museum \\
\hline
\end{tabular}

ment for 4 minutes with a partner of the same classroom chosen by their teacher. On the second day, the entire class came together, and children took turns playing in the system with a different partner from the day before with their classmates and teacher present.

\section{Experience 2: Lands of Fog}

Lands of Fog [2] is a collaborative virtual environment designed for children with autism to practice socialization and collaboration while playing with a typically developed partner. Users move through a variety of exploratory objectives, as the system responds to their bodily movement, gestures, and location in a 6 meter in diameter floor projected playing field. The system supports two users at a time, and the primary engagement mechanism is the exploratory nature of the program, as users must discover features of a virtual world which is covered by fog.

The system was tested in three different settings, with minimal directions before playing in order to encourage exploration of game possibilities. First, we conducted a series of laboratory trials with 14 children with autism between the ages of 10-14 who played with a typically developed partner. Each session lasted for 15 minutes, and was conducted in a university laboratory. Parents, two researchers and a psychologist were present during the experiments. Second, the system was tested in an elementary school setting in London with a special needs program. The system was installed in the gymnasium of the school, and over the course of one week, 20 children with autism came to play with a typically developing partner from the same school. The children played for 15 minute sessions, which were supervised by a member of the special educational needs staff and two researchers. Finally, the system was installed in a science museum for 4 days, during which 1700 student and families came to visit. Children could enter and leave the system as they wanted. In this setting, a researcher was available to facilitate the game. Two participants played at a time, and some smaller children were accompanied by a an older sibling or family member.

\section{Experience 3: Pico's Adventure}

Pico's Adventure was a Microsoft Kinect-based video game created to elicit social behaviors in children with autism collaborating with a peer or a family member [4]. The game invited children to help a lost alien to return to its home planet. The game consisted of four levels which started with a single player session to become acquainted with the system. In subsequent levels, players would collaborate with peers or family members to complete game tasks. The children operated the system with their bodily movements as they stood in front of a large TV screen.

Pico's Adventure was tested with 20 children aged 5-7 who participated in four experimental sessions of up to $15 \mathrm{~min}$ utes each. The system was installed in a hospital room used for autism therapy. As an introduction to the system, children were explained the goals and game narratives. 
Parents, a therapist and a researcher were present during the sessions, and parents actively participated as collaborators in two of the four sessions. Later the system was installed in an art museum for a weekend during a technology fair geared towards people with special needs. During this session, 11 users with various disabilities played with the system. Visitors could approach the scenario at their will and play for the duration of time that they wished. A researcher was present and users were accompanied by family members.

\section{Experience 4: NanoZoom}

NanoZoom was an interactive installation created for general audiences, to help users conceptualize the size of objects in the nanoscale in a playful and collaborative way

[5]. The system was based on a large multi-touch surface where users could place and resize virtual representations of various familiar objects. As players engaged in exploring the game, they could enter a smaller scale by zooming into the virtual environment, making the objects 10x larger. Selected objects would then overflow from the sides of the interactive table onto a large floor projection of $10 \times 4.5 \mathrm{me}$ ters. This also served as an invitation for participation and discussion from nearby museum visitors.

NanoZoom was tested in two different environments. First a series of experimental trials was conducted with 64 children, aged between 11-13 years old, in a sectioned-off area of a science museum. Children played for a maximum of 10 minutes. Children were briefed on how to use and interact with the application, and were asked to explore all possible scales. The system was then installed on the exhibition floor of the museum, which was open to the public over the course of 4 months. During this time, users could come and go as they wanted, ranging from players who would individ- ually navigate through the whole experience by themselves, to more than 12 children playing at the same time.

\section{Observations}

Laboratory trials

During the invitation phase of Lands of Fog, as children entered the play arena, their movements were generally slow and cautious. They spent the first few minutes walking through the scenario, observing parts of the virtual environment. At this point, a few children became disengaged if a long time passed without any significant game actions. As they learned about the game in the exploration phase, most children increased their actions and conversation towards the latter half of the 15 minute session. A common sentiment which was expressed from players was the confusion about the purpose of the game. However, this expression was not made in the exhibition sessions, when players had the opportunity to come and go from the scenario as they wished.

During the exploration phase of Nanozoom, children tended to stand in front of the large multi-touch screen and quickly cast a new object from the selection menu. During the initial scales children would explore the objects by moving them around the interactive surface, but as children advanced to the immersion phase, their behavior was less exploratory and focused towards reaching the final scale.

Museum setting

In the invitation phase of Pico's Adventure, many participants would approach the system cautiously and stand a short distance away, glancing furtively towards the system. When they began to explore the system, the participants often showed pleasure at the simple act of seeing themselves on the screen and having an impact on the virtual environment. During the exploration phase, users would often call 
a family member or friend over to join in playing the game with them. Only one user used the system in single player mode. Many users did not immediately understand the concept of the collaborative actions, but after a brief mediation from the researcher, they pursued the collaborative goals.

For NanoZoom, museum visitors would approach the table in a cautious manner. Many users first observed the information panels around the installation. During the invitation phase, if another person was already interacting with the system, people would normally observe from outside the floor projected surface. When objects overflowed from the table bystanders were engaged to moved close to the multitouch surface, typically turning to face the same direction as the main user was facing. Many users would then interact with the objects of the table, while a main user would still have the role of orchestrator of the shared experience.

From both experiences, we saw that in the exhibition settings, the users' awareness of the context of the system appeared to be more shaded by their own intrigue, and their understanding of what to do was guided by the possibilities that they perceived based on the affordances of the system. This process of gradual discovery allowed users to create their own rules as they explored and interacted with the system. During this process, we could say that the rules and understanding of what was happening in the installation, was formed on their subjective perceptions of their explorations and the intrinsic motivation to understand how the system worked. This poses a difference when compared to the experimental setting, where users are brought to the setting of the interactive experience and guided to play for a certain period of time, which could have influenced their understanding of expectations of the experience. The most observable difference between the laboratory and exhibition setups was the curiosity which players showed outside of the formality of controlled trials, during the invitation and exploration phases of play. This is consistent with the indicators of internal motivation, i.e., trying to understand how the game works and what is its purpose.

\section{Hospital setting}

In Pico's Adventure hospital trials, although children were told to explore possible interactions with their body to achieve their goals, during the invitation phase, after the first minutes of exploration, children would tend to stop moving and turn to the therapist to ask for help on how to achieve their goal. Once children discovered or were explained how to interact with the system, they would quickly explore the possibilities within the game trying to achieve the goals set forth by the system. Nonetheless, children tended to ask the therapist for help whenever they did not achieve their short-term goals.

One way this setting differs from other contexts is that when players were explicitly explained the rules of play, the interactions at their disposition and what was their goal, they would tend to rely more on the psychologist and the researchers when problems occurred. Although the presence of authoritative figures is also a resource for the understanding of the experience by the users, it might be also a distraction when interaction designers try to understand how users approach their design and setting, and how it will be used in more ecological settings.

\section{Classroom setting}

In the elementary school setting of Lands of Fog, we observed a higher level of formality among students while playing than in the laboratory and exhibition environments. This might be due to the fact that their teachers were present instead of their parents. At the beginning of the week, the students were somewhat slow to catch on to the gameplay mechanics, compared to the laboratory trials. This picked 
up towards the end of the sessions, and as the time spent learning to play lessened, we also saw a shallower depth of actions that the children engaged in while playing. Many spent the entire game engaging in the same initial mechanics that they learned during the primary stages of gameplay, even though there was additional content to explore. Additionally, a sort of language was developed between participants, as we saw that words like "leveling up" to describe changes in avatar texture were increasingly common towards the end of the sessions. We attributed this to the possibility the players might have shared information between sessions with other classmates, which led to a common understanding regarding gameplay goals.

In the classroom setting for GenPlay, originally students played the system alone with a partner, externalizing their impressions as they discovered how the system functioned. On the second day, when a teacher was present and classmates took turns playing in the system, we observed less communication between children who were actively playing in the system, as the majority of communication was between players and the children spectators. In this way, the child spectators stayed in the invitation phase for an extended time, as they could preview the system while their classmates were playing. In this case, the spectators played an important role in lending support to the children playing, pointing out observations and actions for the players to try. When it was their turn to play, children could try interactions discovered by the other students, and discovery of the system went much faster than during the isolated play setting. Teachers were asked to encourage children to participate, and when one teacher became involved in supporting the children who were playing, we observed an increase in engagement from the surrounding children as well. Conversely, as a teacher became involved in another task while children were playing, the students also dedi- cated more attention to side activities than actively engaging with the students playing.

\section{Conclusion}

Across the settings presented, users relied on different methods to form their understanding of the systems during the initial phases of play. In experimental settings where previous knowledge or human mediation was available, exploration of interaction features was limited, as users deferred to goal-directed behaviors and searched for an overarching purpose. In the exhibition and classroom settings, the understanding that the children gave to the system was based on their experience and on the intersubjective process that happened with other users of the experience. Depending on the characteristics of the setting or how the experience is introduced to users, the context can greatly affect immersion and exploration of game phases, and the formation of user motivation. Further analysis on this topic can aim to understand how this motivation can work towards greater player engagement with respect to project aims, such as education or socialization in a multiuser setting.

\section{Acknowledgments}

We would like to thank the European Commission for funding the Pico's Adventure project. We would like to note that this publication reflects the views only of the authors, and the Commission cannot be held responsible for any use which may be made of the information contained therein. We would also like to thank La Caixa Foundation for funding Lands of Fog as part of the RecerCaixa 2013 grants.

\section{REFERENCES}

1. Hugh. Beyer and Karen. Holtzblatt. 1997. Contextual Design: Defining Customer-Centered Systems. Morgan Kaufmann. 472 pages. 
2. Ciera Crowell, Joan Mora-Guiard, and Narcis Pares. 2017. Impact of Interaction Paradigms on Full-Body Interaction Collocated Experiences for Promoting Social Initiation and Collaboration. HumanComputer Interaction (sep 2017), 07370024.2017.1374185. DOI : http://dx.doi.org/10.1080/07370024.2017.1374185

3. Linda de Valk, Tilde Bekker, and Berry Eggen. 2015. Designing for social interaction in open-ended play environments. International Journal of Design 9, 1 (2015), 107-120. www.ijdesign.org

4. Laura Malinverni, Joan Mora-Guiard, Vanesa Padillo, Lilia Valero, Amaia Hervás, and Narcis Pares. 2016. An inclusive design approach for developing video games for children with Autism Spectrum Disorder. Computers in Human Behavior (jan 2016). DOI:

http://dx.doi.org/10.1016/j.chb.2016.01.018

5. Joan Mora-Guiard and Narcis Pares. 2014. "Child as the measure of all things": The Body as a Referent in Designing a Museum Exhibit to Understand the
Nanoscale. Proceedings of the 2014 conference on Interaction design and children - IDC '14 (2014), 27-36. DOI :

http://dx.doi.org/10.1145/2593968.2593985

6. Donald A. Norman. 2013. The Design of Everyday Things. (2013). DOI :

http://dx.doi.org/10.1002/hfm. 20127

7. Andrew Polaine. 2010. Developing a Language of Interactivity Through the Theory of Play. Arts Social Sciences PhD (2010). https:

//opus.lib.uts.edu.au/handle/10453/20225http:

//epress.lib.uts.edu.au/dspace/handle/2100/1071

8. Kevin Saunders and Jeannie Novak. 2012. Game Development Essentials: Game Interface Design. Delmar, Cengage Learning. 384 pages.

https://www . amazon. com/

Game-Development-Essentials-Interface-Design/ $\mathrm{dp} / 1111642885 / \mathrm{ref}=\mathrm{dp}$ 